\title{
PROJETO HORTA EDUCATIVA: EDUCAÇÃO AMBIENTAL E NUTRICIONAL EM PRÁTICA HOLÍSTICA.
}

Marcela Lima Pedro ${ }^{1}$

Felipe dos Santos de Melo²

Adriano da Silva Oliveira ${ }^{3}$

RESUMO: O Centro de Convivência Infantil (C.C.I.) da UNESP- F.C.T. de Presidente Prudente é um espaço que foi idealizado com a proposta de auxiliar, proporcionar a prestação de serviços necessários ao acolhimento, ao atendimento e à socialização de crianças de até seis anos de idade, filhos ou dependentes legais de servidora (técnicoadministrativa, docente) e alunos da F.C.T., que esteja no exercício de suas funções. Neste ano de 2013 a UNESP, através do convênio firmado com o Fundo Social de Solidariedade do Estado de São Paulo, vem desenvolvendo em seus C.C.I. o Projeto Horta Educativa, que consiste em implantar hortas educativas em unidades de ensino públicos como instrumento de educação ambiental e alimentar de forma holística, vivenciada, que estimule a compreensão da relação meio ambiente, alimentação saudável, saúde, cidadania e qualidade de vida. Configura-se como uma forma alternativa, diferenciada da prática de ensino-aprendizagem, tomando as crianças como protagonistas da realização das atividades. Portanto, este trabalho visa

\footnotetext{
${ }^{1}$ Graduanda do curso de Engenharia Ambiental, UNESP-FCT. pedro.limarcela@gmail.com

${ }^{2}$ Graduando do curso de Geografia, UNESP-FCT. felipe.s.melo12@gmail.com

${ }^{3}$ Graduando do curso de Geografia e Assistente Operacional I do Centro de Convivência Infantil da UNESP-FCT. adriano@fct.unesp.br
} 
apresentar os resultados obtidos nestes seis meses iniciais de desenvolvimento do projeto.

Palavras-chave: Educação ambiental. Educação alimentar. Centro Convivência Infantil.

\section{INTRODUÇÃO}

O Centro de Convivência Infantil Chalezinho da Alegria (C.C.I.), atualmente localizado na área norte do campus da UNESP- Faculdade de Ciências e Tecnologia (F.C.T.) de Presidente Prudente foi inaugurado em 1987, na direção do Prof. Adj. Marcos Alegre.

Sua concretização surgiu da reinvindicação da comunidade da F.C.T. (servidores técnico-administrativos, docentes e alunos) sobre a necessidade de conciliar o cuidado e educação infantil de seus filhos e filhas, enquanto se dedicavam às suas funções profissionais.

Desde então, o espaço é destinado a crianças de três meses a seis anos de idade priorizando a alimentação adequada, cuidados médicos, higiene corporal, repouso em ambiente adequado, atividades lúdicas variadas de caráter pedagógico, visando o desenvolvimento da percepção da criança de acordo com suas faixas etárias. São dinâmicas elaboradas e executadas pelas educadoras que incentivam a prática em grupo, a comunicação e alfabetização.

De acordo com algumas demandas atuais, o C.C.I. vem buscando o envolvimento de projetos para ensino infantil que abordem a temática meio ambiente, práticas alimentares saudáveis e qualidade de vida, uma vez que esta necessidade é latente, para que não se reproduzam os mesmos hábitos errôneos da grande maioria da população adulta da sociedade atual.

Segundo pesquisas do IBGE (2010), nos últimos 20 anos a obesidade infantil quintuplicou e aliados a ela, houve um aumento nos índices de doenças cardiovasculares, diabetes e deficiências nutricionais, uma vez que se encontra arraigada à ideia do estereótipo da criança saudável é criança "fortinha", logo este 
conceito sobre alimentação saudável deve ser trabalhado desde a primeira infância, nas escolas e principalmente com a participação da família.

Já os aspectos relacionados à temática meio ambiente são mais difundidos atualmente na educação infantil, uma vez que a educação ambiental em 1981 foi consolidada como instrumento da Política Nacional do Meio Ambiente (Lei no 6938/1981) e posteriormente através da Política Nacional de Educação Ambiental (Lei no 9.795/1.999) considerado "componente essencial e permanente da educação nacional, devendo estar presente, de forma articulada, em todos os níveis e modalidades do processo educativo, em caráter formal e não-formal”.

Segundo o Ministério da Educação (2007, p. 15) educação ambiental objetiva:

[...] fomentar processos continuados que possibilitem o respeito à diversidade biológica, cultural, étnica, juntamente com o fortalecimento da resistência da sociedade a um modelo devastador das relações de seres humanos entre si e destes com o meio ambiente.

Porém a esta temática em muitas escolas é tratada de forma fragmentada, distanciada do próprio meio e das dinâmicas das relações ecológicas, onde não há uma sensibilização e uma aproximação do educando em relação à natureza, portanto, não os inserindo como integrantes do meio ambiente que os cercam.

Tendo em vista estas necessidades, neste ano de 2013 através de uma parceria entre a UNESP, a Secretaria de Agricultura e Abastecimento de São Paulo e o Fundo Social de Solidariedade implantaram no Centro de Convivência Infantil o Projeto "Horta Educativa".

A Horta Educativa também contou com o apoio da TV Cultura, que cedeu a utilização das imagens da série infantil "Cocoricó” para ilustração do material didático.

O projeto consiste em implantar hortas educativas em unidades de ensino públicas (Centros de Convivência Infantil dos campi da UNESP em um primeiro momento) e tem como objetivo fortalecer o trabalho educacional através da formação de valores sociais, culturais e alimentares compatíveis com a preservação da cultura do país e do meio ambiente, sensibilizando os alunos a quanto à importância da boa alimentação para um crescimento saudável e integrando, a partir da horticultura, os diferentes conteúdos curriculares da educação infantil. 


\section{DESENVOLVIMENTO}

\subsection{MATERIAIS E MÉTODOS}

Para nortear o projeto foram disponibilizados como material os cadernos informativos, que direciona a organização e execução das atividades: Caderno do Educador; Caderno de Atividades da Criança; Caderno do Cuidador da Horta e Caderno da Família, como ilustrado abaixo na Figura 1.
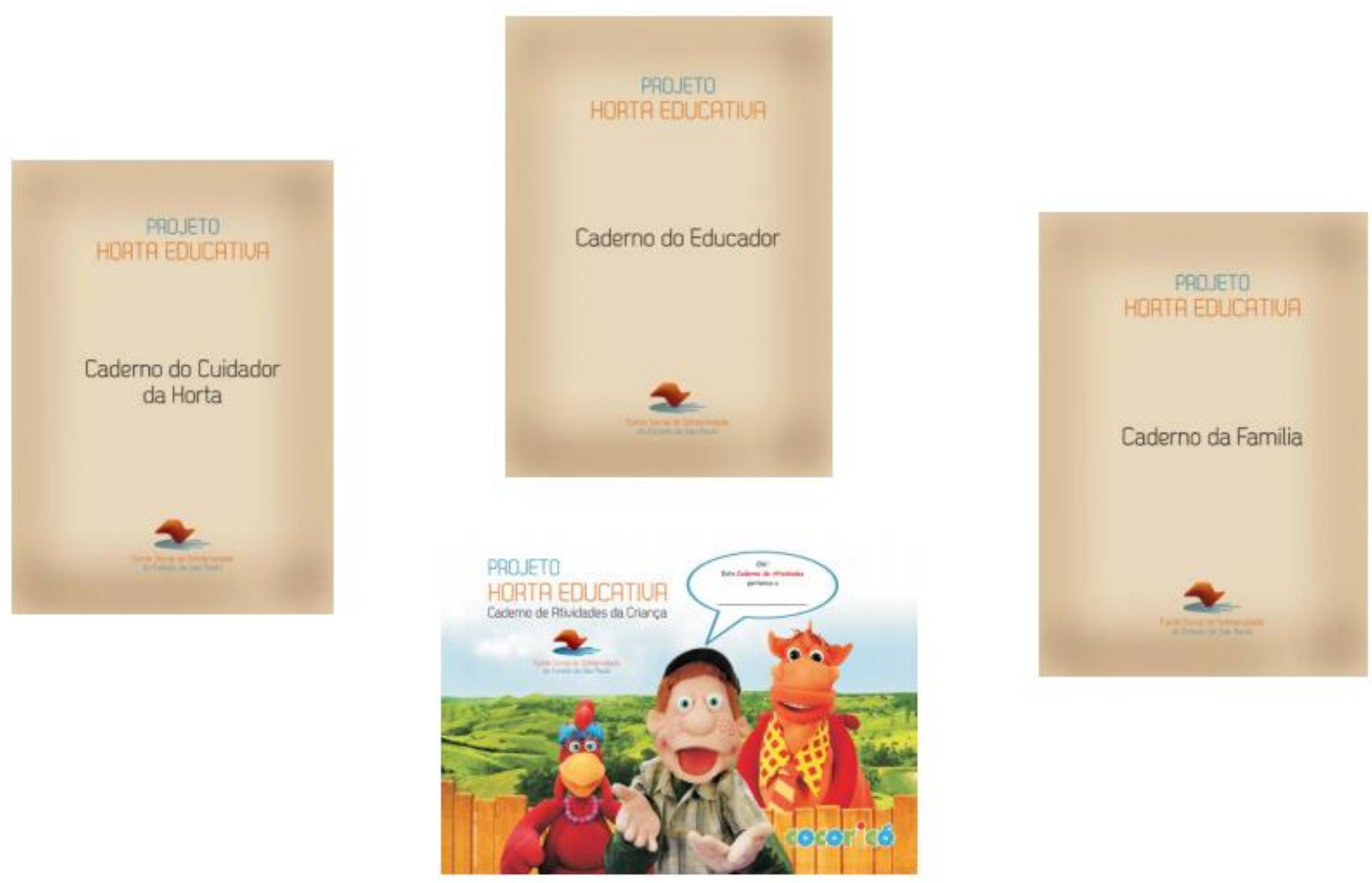

Figura 1 - Cadernos informativos do projeto Horta Educativa.

Fonte: http://www.fundosocial.sp.gov.br/a2sitebox/arquivos/documentos/122.pdf

O Caderno do Educador possui um conteúdo relacionado às atividades propostas pelo projeto. Exercitando junto aos alunos diversas abordagens práticas e teóricas através de dinâmicas de percepção do ambiente, trabalhando com as temáticas: água, ar, solo, luz, o desenvolvimento e evolução do ciclo de vida das plantas, e a composição nutricional de alguns alimentos. 
O Caderno das Crianças é na verdade uma das concretizações dos resultados do projeto. Ele compila a visão das crianças em relação às atividades desenvolvidas, com espaço para o desenho e colagem da observação e interpretação dos conteúdos propostos.

O Caderno do Cuidador da Horta aborda de maneira orgânica desde o plantio das sementes que são isentas de defensivos agrícolas à produção dos canteiros e o controle de pragas. Também contempla aspectos positivos para a fertilidade do solo e a destinação adequada dos resíduos orgânicos gerados no espaço do C.C.I. através da técnica de compostagem.

Já o Caderno da Família traz aspectos relevantes à prática da alimentação saudável, destacando a orientação e composição nutricional de alguns alimentos, melhor período para o consumo e algumas receitas nutritivas, que enfatizam o reaproveitamento de partes vegetais que muitas vezes são descartadas.

Além de todo o material didático oferecido pelos órgãos estaduais envolvidos no projeto, são disponibilizadas algumas ferramentas para e confecção dos canteiros e da própria horta, como representado na Figura 2 a seguir.
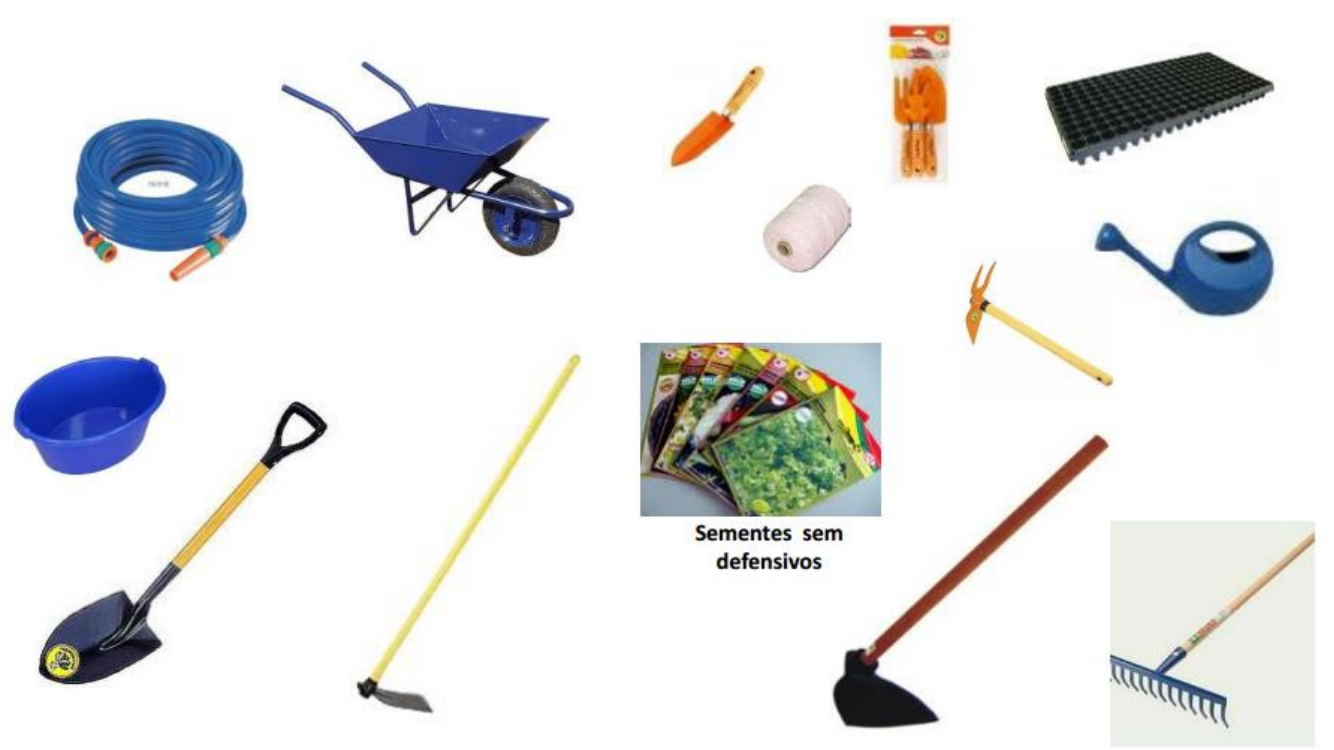

Figura 2 - Ferramentas disponibilizadas para a execução do projeto: mangueira, carriola, pás, enxadinha e rastelo de mão, barbante, sementeiras, regador, rastelo, enxada, enxadão, bacia, e sementes sem defensivos agrícolas.

Fonte:http://www.fundosocial.sp.gov.br/a2sitebox/arquivos/documentos/122.pdf 
Precedendo o início da execução do projeto, o educador e o cuidador da horta participam de um curso de capacitação para adquirir as noções básicas de implantação da horta.

\subsection{RESULTADOS E DISCUSSÃO DOS RESULTADOS}

Até este presente mês de setembro foram realizadas um total de 20 atividades referentes à Horta Educativa, distribuídas semanalmente junto ao cronograma de atividades do C.C.I., que são documentadas através de fotos e vídeos produzidos pelas educadoras e estagiários, e também pelos desenhos e pinturas das crianças.

Para este trabalho foram selecionadas algumas das atividades já realizadas para a apresentação dos resultados.

Inicialmente o local escolhido para a implantação da horta, representado na Figura 3, era uma área onde as crianças não tinham acesso e nenhuma atividade era realizada. O solo, totalmente inadequado, apresentava-se repleto de entulho e fragmentos de rochas, muito compactado, e recoberto por gramíneas. Portanto, a atividade significou também o ganho deste espaço ocioso como uma área experimental de prática de horticultura, educação ambiental e nutricional.

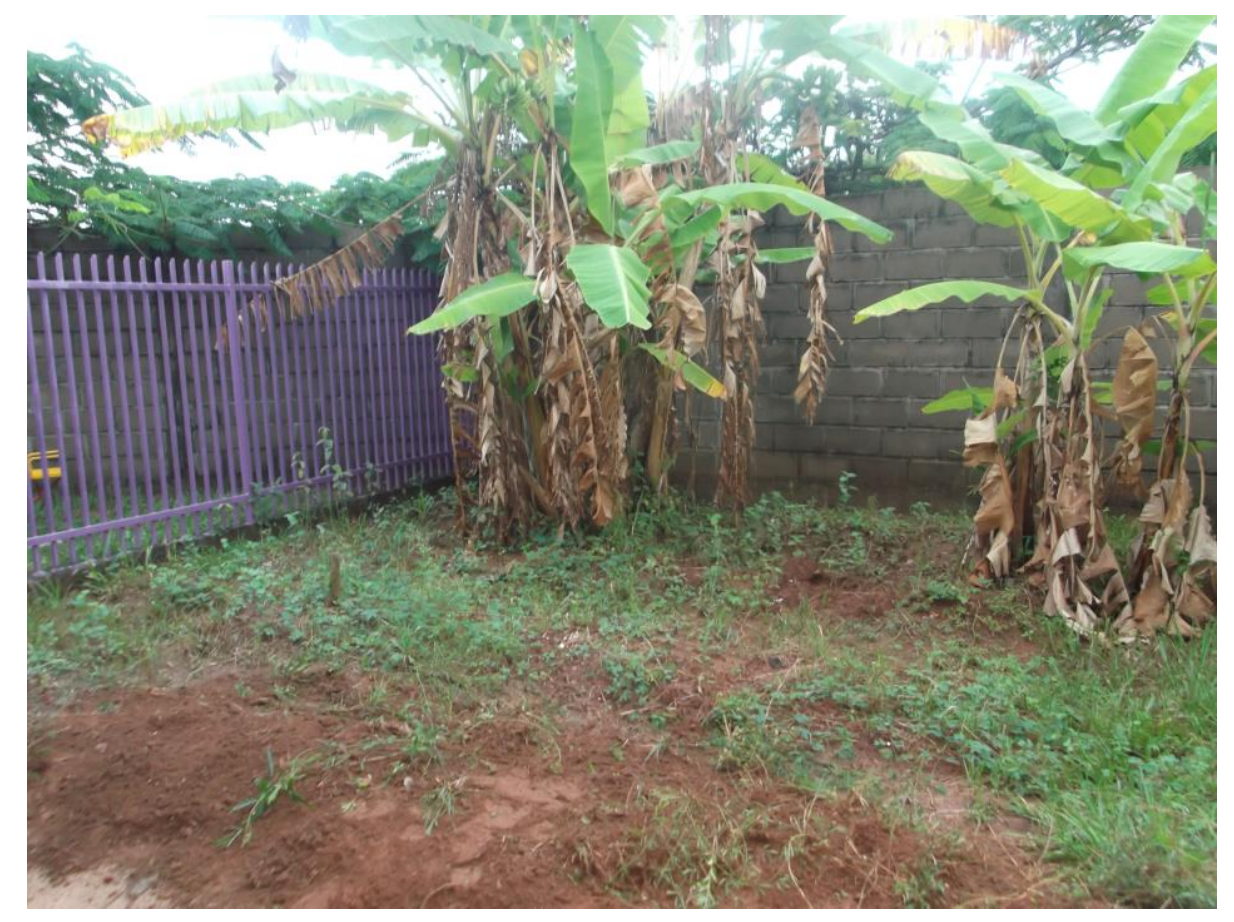

Figura 3 - Área escolhida para a implantação da horta. Fonte: Acervo da equipe. 
Antes de adequar a área para o plantio das hortaliças, levaram-se as crianças para o contato com o local para eles observarem a área e posteriormente desenharem o espaço da futura horta. A Figura 4 é a observação de uma das crianças, desenhada no Caderno da Criança.

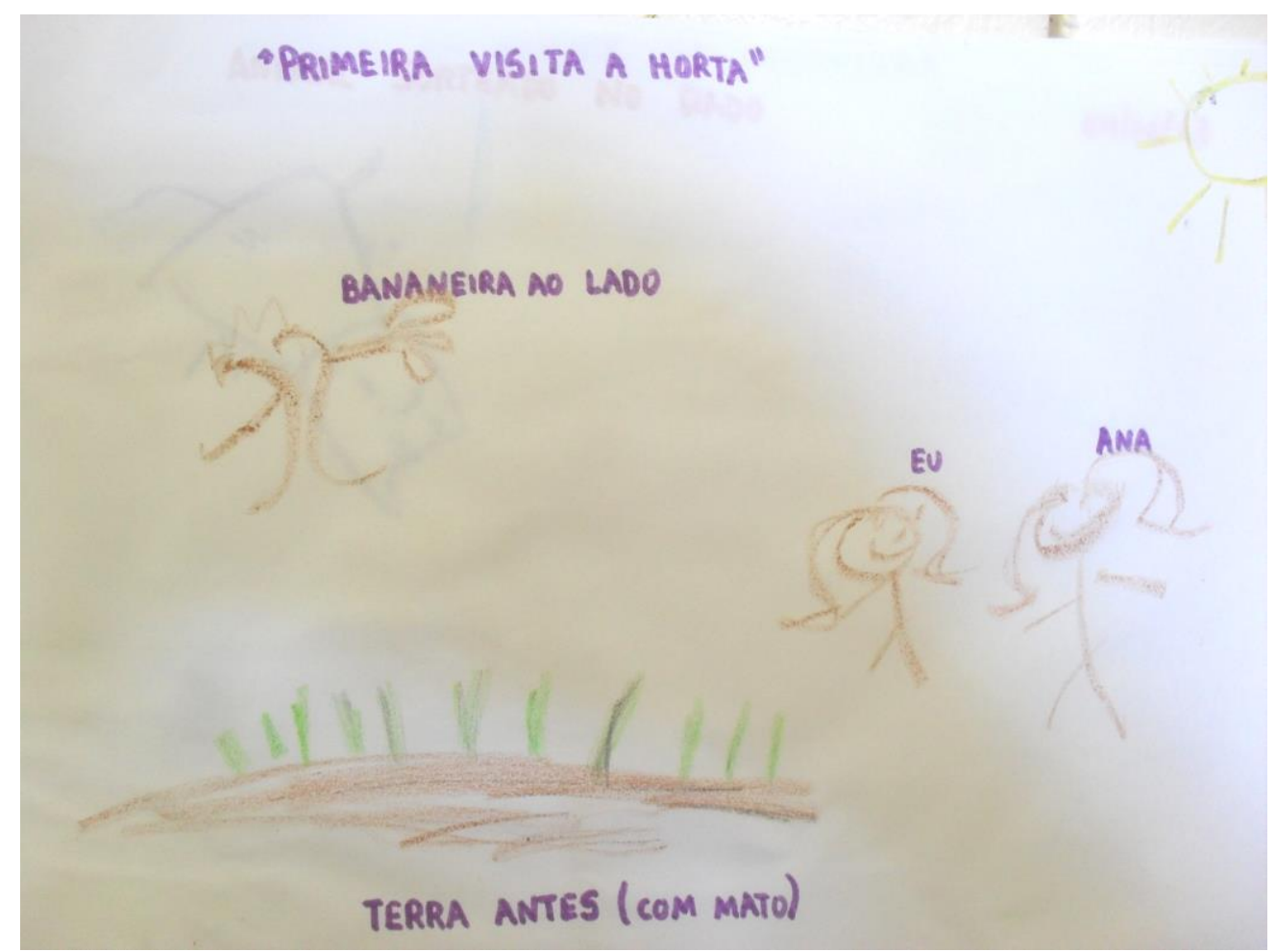

Figura 4 - Desenho de uma das crianças representando o local da futura horta. Fonte: Acervo da equipe.

Com a ajuda de servidores do campus da F.C.T. e alunos de Engenharia Ambiental e Geografia, o espaço foi limpo, estruturado e preparado para o início de uma horta, e a terra que antes imprópria para o cultivo de qualquer hortaliça, foi acrescida de terra vegetal, adquirida através da intermediação de um dos estagiários que colaboram com o projeto.

A primeira atividade realizada após a adequação do local da horta foi o plantio das sementes de alface na sementeira. Uma experiência inédita e inesquecível para as crianças, pois, tiveram contato com as sementes, sentiram o cheiro da terra, fizeram buraquinhos com os dedos e depois regaram o com regador. As crianças acompanham e desenham as etapas de cada atividade: a germinação das sementes plantadas, o replantio nos canteiros e o crescimento da antes pequena semente em uma alface que 
produz pendão de flores. Assim, aprendem que a planta como os seres humanos precisam de água, sol e muito cuidado para se desenvolver. A Figura 5 foi fotografada no momento em que as crianças estão questionando como que a semente consegue sair da terra.

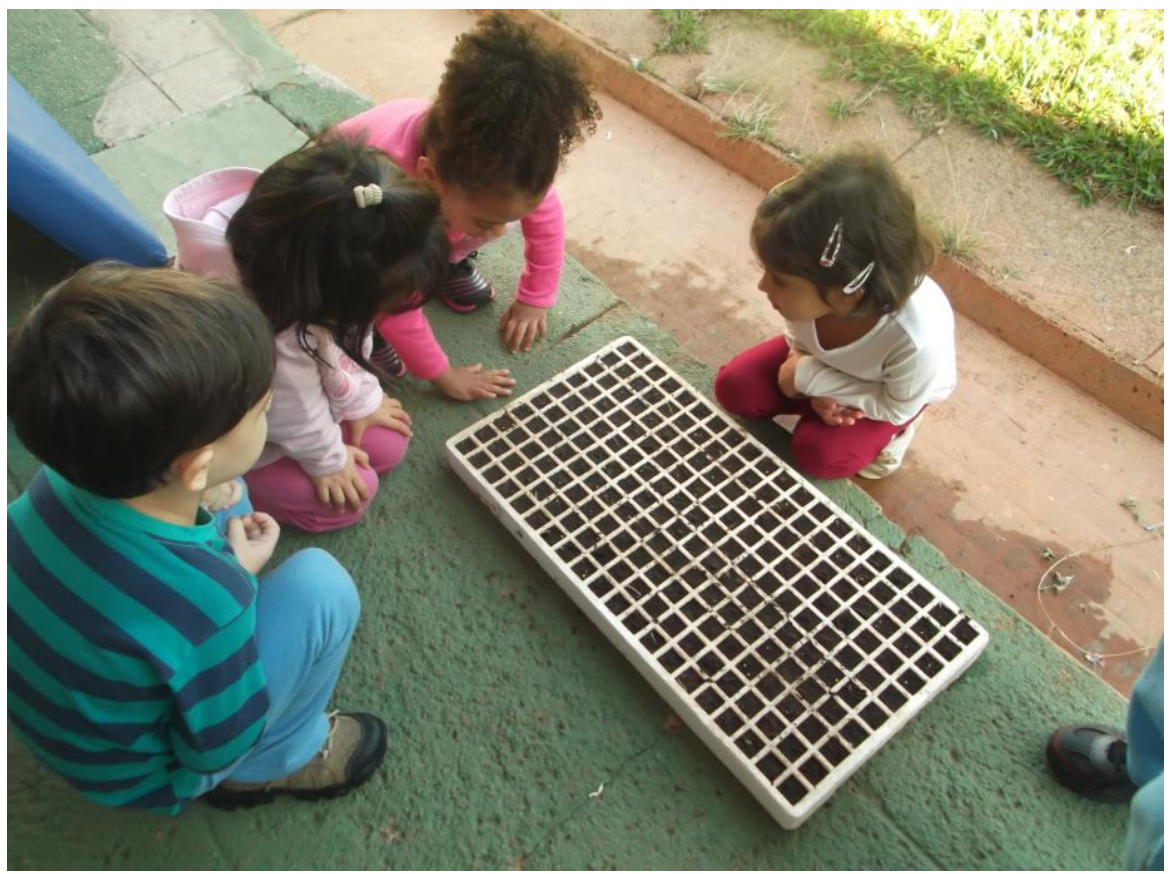

Figura 5 - Observação da germinação das sementes de alface. Fonte: Acervo da equipe.

A segunda atividade realizada foi a prática da compostagem. Uma das mais apreciadas pelas crianças, pois elas tem contato com resíduos orgânicos da cozinha, capim seco e serragem, tudo que é necessário para produzir o adubo orgânico para ser utilizado na horta. A primeira compostagem, representada na Figura 6, foi realizada no mês de junho em um espaço próximo a horta e sem cobertura. 


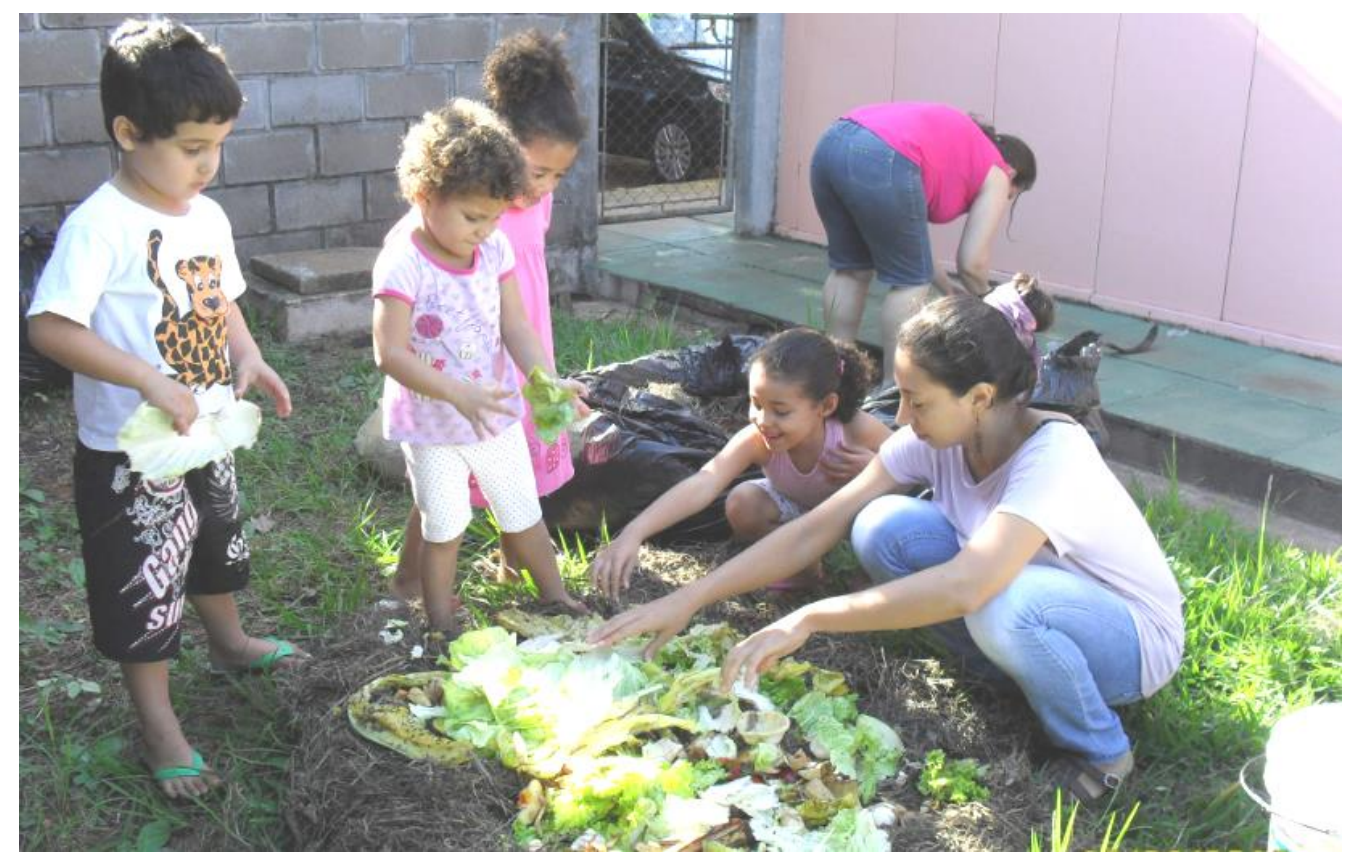

Figura 6 - Elaboração da primeira leira. Fonte: Acervo da equipe

Todo o procedimento foi bem sucedido. As crianças acompanharam dia após dia, perguntaram para que servia o composto, observaram a transformação dos alimentos através de sua decomposição, sentiram o cheiro que o composto exala e, principalmente, ficaram impressionadas com o calor que a leira produzia. $O$ composto aquecia bastante e, por algumas vezes, utilizou-se termômetro para verificar a temperatura no interior da leira que se aproximava de $50^{\circ} \mathrm{C}$. Tudo foi novidade para as crianças. Após retornarem a sala de aula, elas utilizaram seu caderno para desenhar o que observaram durante a elaboração da leira e, após 15 dias, o que tinha sido decomposto e o que ainda estava inteiro. Surgiram muitas perguntas e curiosidades. $O$ que elas mais gostavam de fazer era colocar a mão no interior da leira e sentir o calor produzido.

A Figura 7 a seguir é referente à prática de compostagem, e foi desenhada por uma das crianças participantes. 


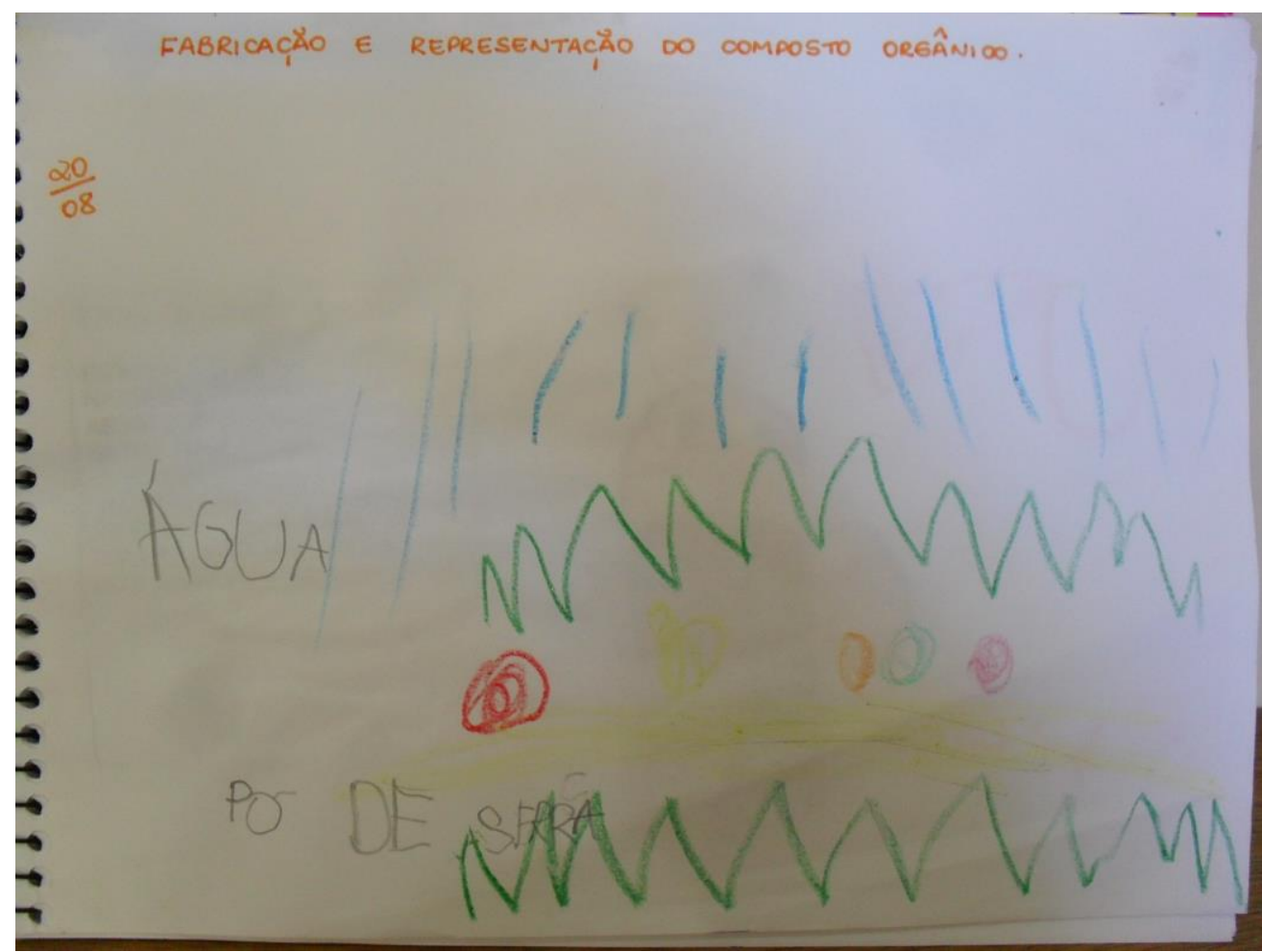

Figura 7 - Elaboração da primeira leira de compostagem desenhada por uma das crianças.

Após a confecção da primeira leira, com o apoio dos servidores da UNESP, foi construída uma composteira adequada, com cobertura, para evitar que o composto fique encharcado e evitar a aproximação de animais.

Outra atividade realizada com as crianças foi a dinâmica dos condimentos. Nesta prática, as mudas que serão plantadas são dispostas no centro de uma roda formada pelas crianças. Muda por muda, através dos sentidos (olfato, tato, visão e paladar) e dicas onde são utilizadas no preparo de diferentes refeições, as crianças tentam adivinhar qual é a planta em questão.

Logo após a dinâmica, as mudas foram plantadas com o auxilio das crianças que também confeccionaram as plaquinhas de identificação, conforme a Figura 8. Esta atividade prática mostrou-se muito produtiva, com a excelente participação das crianças que se interessaram quanto diversidade de espécies de plantas. 


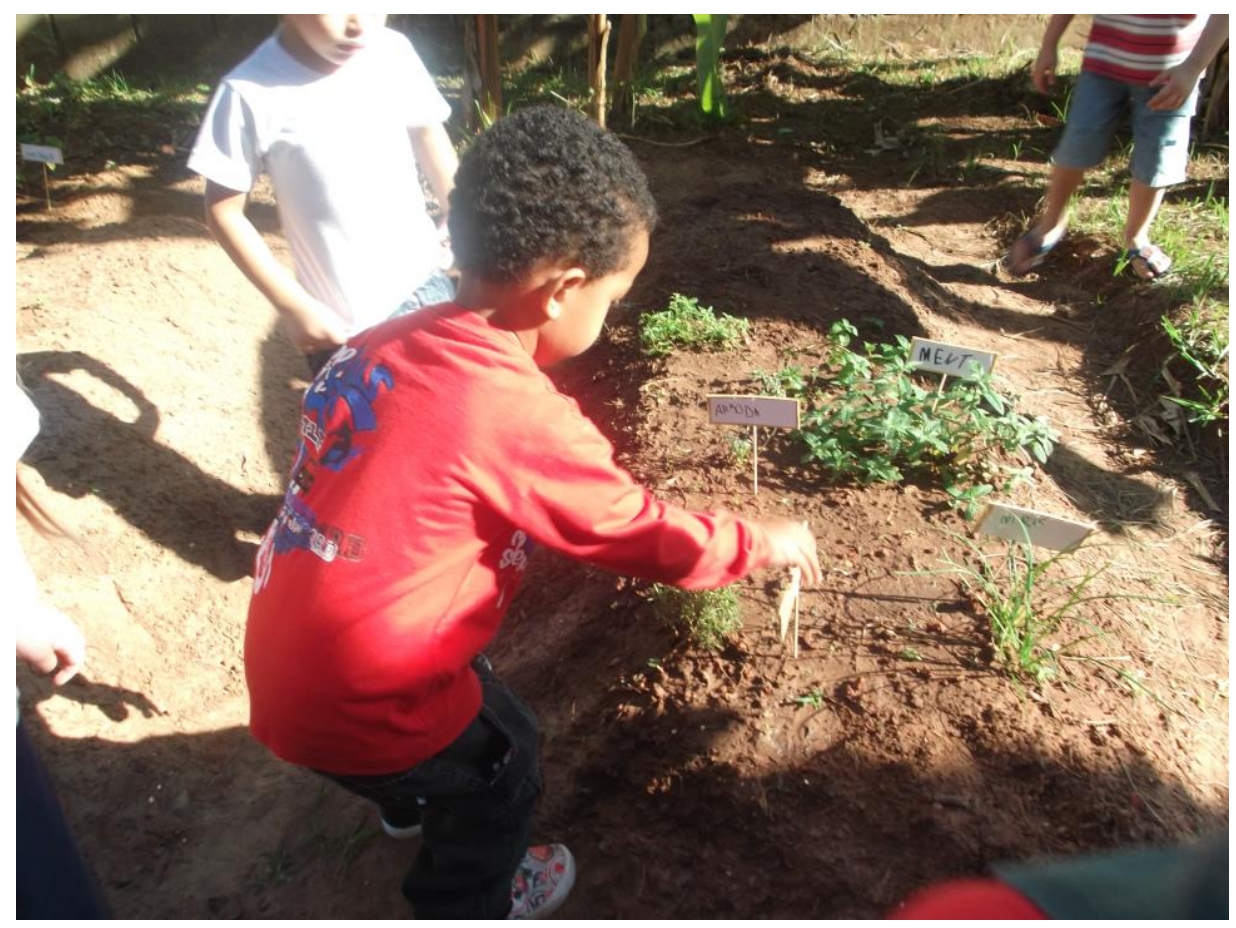

Figura 8 - Plantio e identificação das mudas de condimentos. Fonte: Acervo da equipe.

Outra atividade realizada, mas com a temática água, foi a confecção de filtros de areia e pedras, representada na Figura 9.

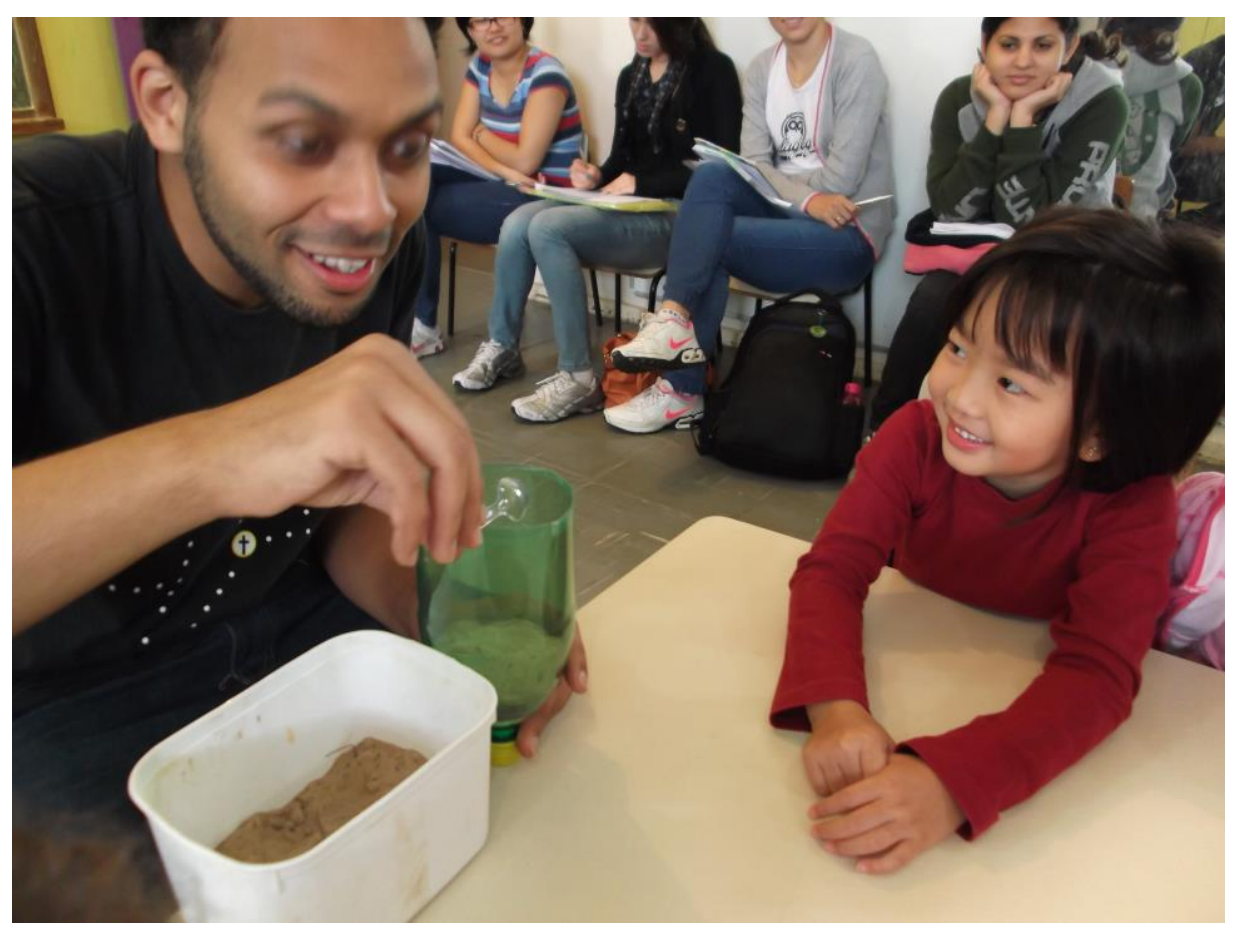

Figura 9 - Confecção do filtro de areia e pedras. Fonte: Acervo da equipe. 
O filtro de água foi confeccionado com garrafas pets que foram cortadas ao meio e com suas bordas protegidas com fita adesiva transparente. Ambas as partes foram usadas: a parte de baixo como copo de armazenamento do liquido já purificado, a parte de cima da garrafa para fazer o filtro, que fica encaixado com o gargalo acoplado no bocal da parte de baixo, da mesma forma como em um filtro caseiro.

Os materiais que compõem o filtro são: o algodão, carvão mineral, areia e as pedrinhas coloridas, cada um com uma granulometria diferenciada.

Após a confecção do filtro, simulou-se filtragem com água e bastante terra, que ao percolar as camadas do filtro, foi coletadas com um aspecto mais límpido.

As crianças admiraram-se e questionaram como só com aqueles materiais filtravam_a água mesmo com terra.

Com relação à importância da boa alimentação, e com o objetivo de mostrar às crianças onde as sementes são encontradas nas refeições, as educadoras confeccionaram barrinhas de cereais.

A maioria das crianças participou com muito entusiasmo e curiosidade perguntando sobre tudo o que viram, desde ingredientes até o processo de preparação. Muitas participaram até o fim de todo o procedimento e ficaram ansiosas para levar ao forno, cortar e experimentar. Mesmo após a preparação e a degustação, houve estranhamento sobre o cheiro e o sabor. As crianças diziam que o gosto era ruim e recusaram a receita. Diante desta reação, percebeu-se que a barrinha de cereais é algo muito distante dos hábitos alimentares das crianças, e que é necessário um maior incentivo para o consumo deste alimento tão nutritivo, à base de frutas secas e cereais.

Logo após a confecção e degustação, as crianças desenharam o que observaram sobre as barrinhas. A Figura 10 é fruto desta atividade. 


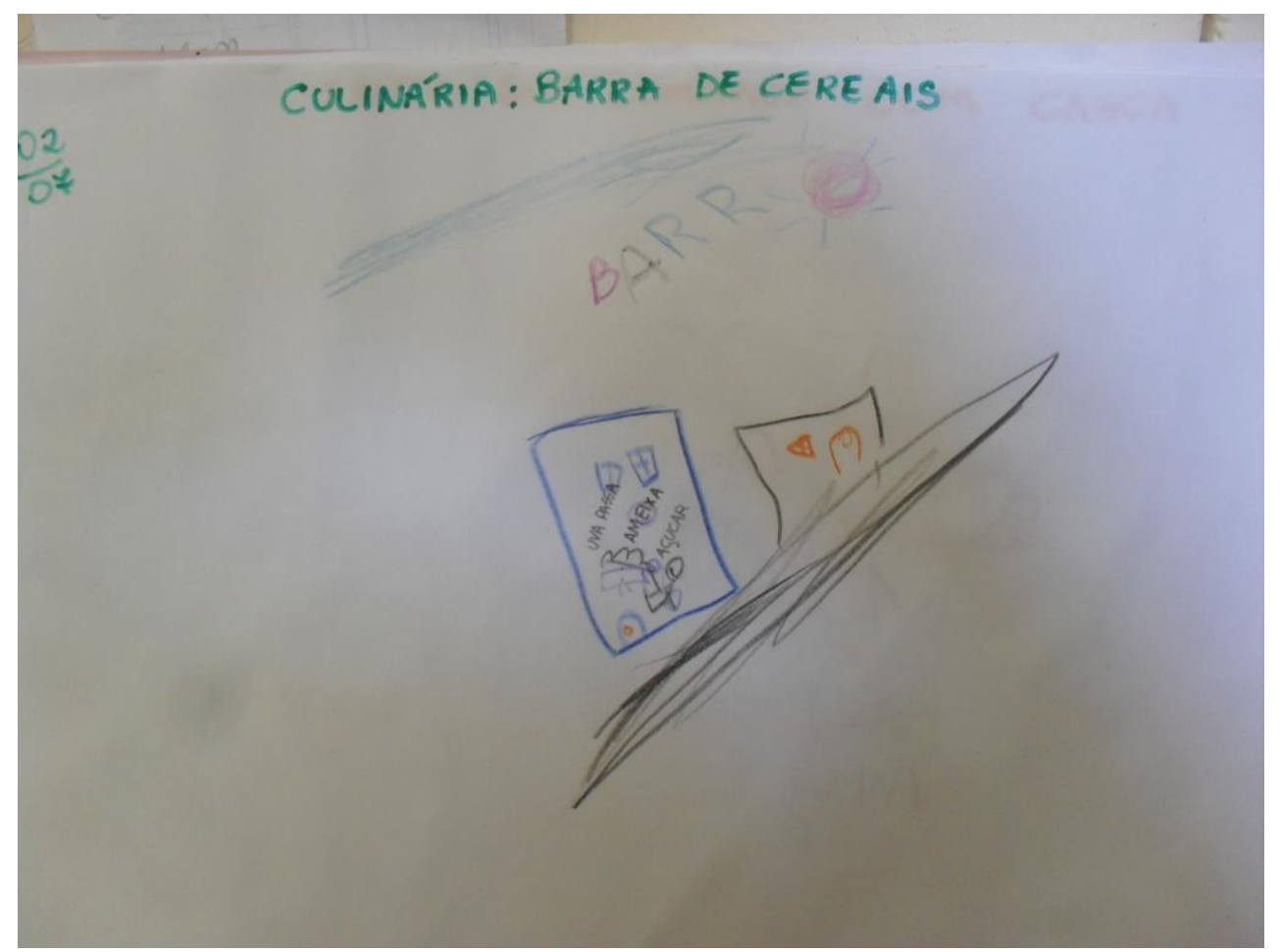

Figura 10 - Desenho da confecção das barrinhas de cereais. Fonte: Acervo da equipe.

\section{CONCLUSÃO}

Apesar da execução do projeto não ter completado ainda seu primeiro ano de desenvolvimento, já se frutificaram alguns ótimos resultados.

Conclui-se que o projeto Horta Educativa configura-se como excelente instrumento para a prática de educação ambiental e nutricional, valorizando a participação das crianças na proposição e desenvolvimento das atividades, tornandoos sujeitos das ações da horta.

As atividades são de fácil assimilação e compreensão, trabalhadas de forma lúdica, o que desperta mais interesse e atenção por parte das crianças, e que posteriormente transformam-se em sujeitos multiplicadores do conhecimento, questionando até as atitudes de amigos e família.

O projeto trabalha não apenas com o processo de construção de valores com as crianças, mas também influencia de forma positiva a prática cotidiana de todos e todas que estão envolvidos. 


\section{REFERÊNCIAS}

Instituto Brasileiro de Geografia e Estatística (IBGE). POF 20082009 - Antropometria e estado nutricional de crianças, adolescentes e adultos no Brasil. 2010.

BRASIL. Lei no 6.938, de 31 de agosto 1981. Dispõe sobre a Política Nacional do Meio Ambiente, seus fins e mecanismos de formulação e aplicação, e dá outras providências. Diário Oficial da União, 31 de agosto de 1981.

BRASIL. Lei no 9.795, de 27 de abril de 1999. Dispõe sobre a educação ambiental, institui a Política Nacional de Educação Ambiental e dá outras providências. Diário Oficial da União, 27 de abril de 1999.

MINISTÉRIO DA EDUCAÇÃO. Vamos cuidar do Brasil: conceitos e práticas em educação ambiental na escola / [Coordenação: Soraia Silva de Mello, Rachel Trajber]. Brasília. Coordenação Geral de Educação Ambiental: Ministério do Meio Ambiente, Departamento de Educação Ambiental: UNESCO, 2007.

Disponível em: http://www.fct.unesp.br/\#!/administracao/nbspcci/ccis-que-lugar-e-esse/ Acesso: 13/09/2013.

Disponível em:http://www.fundosocial.sp.gov.br/a2sitebox/arquivos/documentos/122.pdf Acesso: 13/09/2013. 